\title{
Modelos de pontos críticos para relacionar o rendimento de grãos de aveia branca com a intensidade de doença no patossistema múltiplo ferrugem da folha - helmintosporiose
}

\author{
Critical-point models to relate white oat yield and disease intensity of the multiple pathosystem \\ leaf rust - helminthosporium blight
}

\author{
João Martinho Nerbass Junior ${ }^{\mathrm{I}}$ Ricardo Trezzi Casa ${ }^{\mathrm{I}}$ Paulo Roberto Kuhnem Júnior $^{{ }^{*}}$ \\ Fernando Gava Amauri Bogo ${ }^{I}$
}

\section{RESUMO}

A ferrugem da folha e a helmintosporiose são as principais doenças fúngicas foliares de aveia branca. Em cultivares suscetíveis, o controle químico não considera o limiar de dano econômico ( $L D E$ ). O objetivo deste trabalho foi obter funções de dano, por modelos de ponto crítico, ao relacionar o dano pela ocorrência simultânea da ferrugem da folha e a helmintosporiose com o rendimento de grãos nas safras de 2006 e 2007, em Lages, Santa Catarina (SC). O gradiente da intensidade das doenças foi gerado por número de aplicações e doses de fungicidas nas cultivares 'UPFA 20' e 'UPFA 22'. Os ensaios consistiram de 10 tratamentos, distribuídos em blocos casualizados, com quatro repetições. As doenças foram avaliadas nos estádios de alongamento, emborrachamento $e$ florescimento. Os modelos de ponto crítico foram obtidos por regressão linear entre rendimento de grãos e incidência (I) $e$ severidade (S). Em 2006, funções significativas foram obtidas para 'UPFA 20' no emborrachamento $(R=6.345-22,07 I)$, enquanto para a 'UPFA 22' foi obtida no alongamento ( $R=5.726-17,96 I ; \quad R=5.160-541,5 S), \quad$ emborrachamento $(R=5.961-21,85 I ; \quad R=5.433-966,8 S) \quad$ e florescimento $(R=6.217-36,41 I ; R=5.539-1.185 S)$. Em 2007, para 'UPFA 20 ', no alongamento ( $R=6.369-55,61 I ; R=4.965-2.911 S)$, emborrachamento $(R=6.620-40,91 I ; R=5.181-1.702 S) e$ florescimento $(R=6.129-32,34 I ; R=5.252-638,6 S)$, e para 'UPFA 22', no alongamento $(R=5.201-41,96 I ; R=4.977$ $657,8 S)$, emborrachamento $(R=5.329-60,51 I ; R=4.238$ $798,1 S)$ e florescimento ( $R=5.604-32,83 I ; R=4.680-588,5 S)$. A produção na cultivar 'UPFA 22' foi mais afetada pela ocorrência das doenças, e a intensidade das doenças no estádio de florescimento apresentou maior relação com o rendimento de grãos. As funções geradas permitem obter o coeficiente de dano para uso no cálculo do LDE em patossistema múltiplo ferrugem da folha e helmintosporiose.

Palavras-chave: Avena sativa, controle químico, dano, Drechslera avenae, Puccinia coronata.

\section{ABSTRACT}

The leaf rust and helminthosporium blight are the main foliar diseases of white oat. The chemical control in susceptible cultivars does not consider the economic damage threshold (EDT). The objective of this research was to obtain the damage functions by critical-point models to relate damage by simultaneous occurrence of white oat leaf rust and helminthosporium blight with yield grains during 2006/07 crop seasons in Lages, SC, Brazil. The gradient of diseases intensity was generated by number of applications and rates fungicides on cultivars 'UPFA 20' and 'UPFA 22'. The trials consisted by 10 treatments distributed in randomly blocks with four replications. Diseases evaluations were done in the elongation, booting and flowering stages. The critical-point models were obtained by linear regression between grain yield and leaf diseases incidence and severity. In 2006, significant function was obtained for 'UPFA 20' in booting stage $(R=6.345$ 22.07I), with 'UPFA 22'. The significant functions were obtained in elongation $(R=5.726-17.96 I$ and $R=5.160-541.5 S)$, booting $(R=5.961-21.85 I ; R=5.433-966.8 S)$ and flowering stages ( $R=6.217-36.41 I ; R=5.539-1.185 S)$. In 2007, the significant functions were obtained in all growth stages evaluated. To 'UPFA 20', the significant functions were in the elongation ( $R=6.369-55.61 I ; R=4.965-2.911 S)$, booting ( $R=6.620$ 49.91I; $R=5.181-1.702 S)$ and flowering $(R=6.129-32.34 I$; $R=5.252-638.6 S)$, while in the 'UPFA 22', were in the elongation ( $R=5.201-41.96 I ; R=4.977-657.8 S)$, booting $(R=5.329-60.51 I ; R=4.238-798.1 S)$ and flowering $(R=5.604-$ 32.83I; $R=4.680-588.5 S)$. The 'UPFA 22' cultivar production was more affected by diseases occurrence and the diseases intensity in the flowering stage showed greater relation with the yield grain. The generated functions allowed obtaining the damage coefficient to use in the EDT in the multiple pathosystem leaf rust and helminthosporium.

Key words: Avena sativa, chemical control, damage, Drechslera avenae, Puccinia coronata.

IDepartamento de Agronomia, Universidade do Estado de Santa Catarina (UDESC), 88520-000, Lages, SC, Brasil. E-mail: a2prk@cav.udesc.br. *Autor para correspondência. 


\section{INTRODUÇÃO}

O sistema de semeadura direta nas lavouras do Sul do Brasil aumentou a área semeada com aveia branca (Avena sativa L.). A aveia pode ser cultivada como pastagem de inverno, silagem, cobertura verde e grãos para alimentação de animais e humanos (FLOSS, 2007).

Doenças podem reduzir a produção de grãos de aveia branca (FORCELINI \& REIS, 2005), destacando-se a ferrugem da folha, causada pelo fungo Puccinia coronata Cda. f.sp. avenae Eriks, com danos no rendimento de grãos na faixa de 57 a $62 \%$ (MARTINELLI et al., 1994), e a helmintosporiose, causada pelo fungo Drechslera avenae (Eidam) El Sharif, sendo importante em lavouras de plantio direto e monocultura (REIS \& CASA, 2007).

O uso de cultivares resistentes é a medida mais eficaz no controle dessas doenças. Esta estratégia de controle, aliada a medidas alternativas como o uso de sementes sadias, tratamento de semente, rotação de culturas e eliminação de plantas voluntárias reduzem fontes de inóculo. A aplicação de fungicidas nos órgãos aéreos se mostra uma medida rápida e eficiente que impede o crescimento das doenças (FORCELINI \& REIS, 2005). Entretanto, a aplicação sem critério técnico e econômico proporcionado pelo modelo convencional de agricultura provoca aumento no custo de produção e contaminação do agroecossistema. No caso de cereais de inverno, a pesquisa dispõe de critérios com base na intensidade de doença ou nos estádios de crescimento (FORCELINI \& REIS, 2005; REIS \& CASA, 2007; INDICAÇÕES, 2008). No entanto, alguns critérios não levam em consideração a relação entre dano e custo de controle, o que pode acarretar em aplicações desnecessárias, elevando os custos de produção, ou ainda, aplicações tardias quando a intensidade da doença ultrapassou o limiar de dano econômico (LDE). O LDE caracteriza-se como critério científico e racional para aplicação de fungicida em trigo (REIS et al., 2000; REIS \& CASA, 2007; INDICAÇÕES, 2008), cevada (REIS et al., 2002), milho (REIFSCHNEIDER \& ARNY, 1983; NUTTER \& JENCO, 1992; WARD et al., 1999; REIS et al., 2007) e aveia branca (REIS et al., 2008).

Independente da cultura torna-se necessária a obtenção de funções de dano em cultivares com reações contrastantes a doenças foliares, sobretudo em patossistema múltiplo, uma vez que as doenças podem ocorrer simultaneamente na mesma planta. Para determinar o dano, analisam-se as relações entre intensidade da doença e dano, utilizando modelos matemáticos como de ponto crítico, múltiplos pontos, integrais, de superfície de resposta e modelos sinecológicos. No modelo de ponto crítico, é possível identificar um determinado estádio de desenvolvimento, no qual a intensidade de doença presente está correlacionada com o dano futuro (BERGAMIN FILHO \& AMORIM, 1996; JESUS JUNIOR et al., 2004).

O objetivo do experimento foi gerar funções de dano por modelos de ponto crítico para o patossistema múltiplo ferrugem da folha e a helmintosporiose, por meio da relação entre intensidade das doenças e rendimento de grãos nas cultivares de aveia branca 'UPFA 20' Teixeirinha e 'UPFA 22' Temprana. Com as funções, obtêm-se os coeficientes de dano para uso no cálculo do LDE.

\section{MATERIAL E MÉTODOS}

Os experimentos foram conduzidos na área experimental do Centro de Ciências Agroveterinárias da Universidade do Estado de Santa Catarina, CAV/ UDESC, Lages, SC, nas safras agrícolas de 2006 e 2007, com altitude de aproximadamente $960 \mathrm{~m}$ em relação ao nível do mar e com solo do tipo Cambissolo Húmico Alumínico Léptico (EMBRAPA, 2008).

As semeaduras da aveia foram realizadas em 12 e 17 de julho de 2006 e 2007, respectivamente, com replantio em 10 de agosto, na safra de 2007, em razão da ocorrência de baixas temperaturas e geadas que ocasionaram morte de plântulas. Os ensaios foram instalados em área de rotação de culturas, em 2006, e sob monocultura, em 2007. As semeaduras ocorreram no sistema de plantio direto com semeadora para parcelas experimentais, marca Semina/Embrapa, regulada no espaçamento de 0,20 metros entre linhas e com densidade de sementes para obter uma populacional final de 250 plantas $\mathrm{m}^{-2}$. Na adubação de base, foram utilizados $300 \mathrm{~kg} \mathrm{ha}^{-1}$ do fertilizante (N-PK), fórmula 10-20-20. A adubação de cobertura foi realizada com as plantas apresentando cinco folhas abertas com $150 \mathrm{~kg} \mathrm{ha}^{-1}$ de ureia ( $45 \%$ de $\mathrm{N}$ ). O controle de plantas daninhas de folhas largas em pósemergência foi realizado com os herbicidas metsulfurom metílico (2,0g i.a. ha $\left.{ }^{-1}\right)$ no perfilhamento e o manejo do azevém (Lolium multiflorum L.), por arranquio manual. $\mathrm{O}$ controle de pulgões e lagartas foi realizado com o inseticida Beta-ciflutrina + imidacloprida $\left(600 \mathrm{~mL} \mathrm{ha}^{-1}\right)$, aplicado no alongamento e emborrachamento.

As unidades experimentais constaram de 10 tratamentos, com parcelas de cinco linhas de semeadura de cinco metros de comprimento. $\mathrm{O}$ delineamento experimental foi de blocos ao acaso, com quatro repetições, totalizando 40 parcelas em cada experimento. Foram utilizadas duas cultivares de aveia branca suscetíveis à ferrugem da folha e 
helmintosporiose, 'UPFA 20' Teixeirinha e 'UPFA 22' Temprana. Cada cultivar e ano constituíram um experimento, e as doses e épocas de aplicação do fungicida, os tratamentos.

O gradiente da intensidade das doenças nas duas cultivares foi gerado pelo número de aplicações e doses de fungicida (uma -afilhamento; duas afilhamento e alongamento; quatro - afilhamento, alongamento, início do emborrachamento e antese), mais uma testemunha ou dose zero, conforme: T1. testemunha; T2. 1/2 da dose indicada, uma aplicação; T3. 3/4 dose indicada, uma aplicação; T4. dose indicada, uma aplicação; T5. 1/2 dose indicada, duas aplicações; T6. 3/4 da dose indicada, duas aplicações; T7. dose indicada, duas aplicações; T8. 1/2 da dose indicada, quatro aplicações; T9. 3/4 da dose indicada, quatro aplicações e; T10. dose indicada, quatro aplicações, conforme metodologia usada por SAH \& MACKENZIE (1987), REIS et al. (2000) e REIS et al. (2002). Os fungicidas usados nas duas cultivares e nos dois anos agrícolas foram piraclostrobina + epoxiconazole, nas doses de 33,25+12,5, 49,87+18,75, 66,5+25g de i.a. ha-1. A primeira aplicação em todos os tratamentos ocorreu no estádio de final de perfilhamento em ambas as cultivares. O intervalo de tempo entre aplicações foi de aproximadamente 20 dias, sendo aplicadas com pulverizador costal de precisão, com pressão constante gerada por gás $\mathrm{CO}_{2}$, com barra de dois metros contendo seis pontas de pulverização, com volume de calda de 200 litros ha $^{-1}$. A metodologia usada para obter o gradiente das doenças com os graus de dano no rendimento constitui-se do método de parcela experimental, usando o modelo de ponto crítico (BERGAMIM FILHO \& AMORIM, 1996).

A intensidade das doenças foi quantificada em conjunto nos estádios de alongamento, emborrachamento e florescimento, avaliando todas as folhas verdes e expandidas de 10 plantas, coletadas ao acaso, nas três linhas centrais da parcela. A incidência foi calculada pelo número de folhas infectadas, dividido pelo número total de folhas, vezes 100 . A severidade foi calculada pelo somatório da percentagem de área foliar infectada, dividido pelo número total de folhas, vezes 100 , realizada sempre pelo mesmo avaliador. Considerou-se infectada a folha com a presença de mancha foliar e/ou pústula de ferrugem com esporulação visível.

A colheita foi realizada manualmente, coletando todas as panículas de aveia em uma área de $0,25 m^{-2}$, em dois pontos dentro de cada parcela. As panículas foram acondicionadas em casa de vegetação de vidro por três dias para a redução dos teores de umidade dos grãos para próximos de 13\%. Após trilhagem em máquina estacionária, foram feitas a limpeza e a pesagem dos grãos, a fim de determinar o rendimento por parcela e por hectare.

Os dados obtidos foram submetidos aos testes das pressuposições do modelo matemático e, em seguida, à análise de variância $(\mathrm{P} \leq 0,05)$. A interação tripla cultivar $\mathrm{x}$ estádio fenológico $\mathrm{x}$ ano foi significativa pelo teste $F$. $(P \leq 0,05)$, gerando as funções de dano para cada cultivar, em cada ano agrícola e estádio fenológico da cultura, por meio da análise de regressão linear entre a intensidade das doenças (variável independente) e o rendimento de grãos (variável dependente). As equações obtidas também foram ajustadas por tonelada, visando a facilitar a comparação dos coeficientes de dano para cada estádio de desenvolvimento da planta nas cultivares e safras agrícolas.

\section{RESULTADOS E DISCUSSÃO}

Houve condições ambientais propícias para desenvolvimento da helmintosporiose e ferrugem da folha nas duas cultivares e safras agrícolas. De julho a outubro de 2006, período que correspondeu aos estádios vegetativos e reprodutivos, as precipitações pluviais somaram 392mm, com temperatura média de $14,7^{\circ} \mathrm{C}$. Para 2007, de agosto a outubro, as precipitações somaram $499 \mathrm{~mm}$, e a temperatura média foi de $15,2^{\circ} \mathrm{C}$.

Na safra 2006, em ambas cultivares, houve predomínio da helmintosporiose no alongamento e emborrachamento, com predominância da ferrugem da folha a partir do florescimento. A maior severidade da ferrugem da folha no final do ciclo coincide com o aumento da temperatura do ar requerida pelo patógeno $\left(18\right.$ a $22^{\circ} \mathrm{C}$ ) (FORCELINI \& REIS, 2005), ocorrida a partir dos meses de outubro e novembro na região de Lages, SC. Na safra de 2007, na ‘UPFA 20’ Teixeirinha, as duas doenças ocorreram de maneira uniforme e, na 'UPFA 22' Temprana, predominou a helmintosporiose nos estádios de alongamento até florescimento.

Houve interação tripla significativa pelo teste $\mathrm{F}$. $(\mathrm{P} \leq 0,05)$ entre ano $\mathrm{x}$ cultivar $\mathrm{x}$ estádio fenológico, gerando 12 funções de danos para a variável incidência e 12 funções de dano para variável severidade (Tabelas 1 e 2). Na 'UPFA 20' Teixeirinha, os valores de dano variaram entre 0,76 e $3,48 \mathrm{~kg} \mathrm{ha}^{-1}$ para cada $1 \%$ de incidência foliar, considerando o rendimento de $1.000 \mathrm{~kg}$ ha $^{-1}$ na safra 2006 (Tabela 1). Em 2007, os danos foram maiores em todos os estádios de desenvolvimento, variando de 5,28 a $8,73 \mathrm{~kg} \mathrm{ha}^{-1}$ para cada $1 \%$ de incidência foliar. Para 'UPFA 22' Temprana, na safra de 2006, os valores de dano variaram entre 3,14 e 5,86kg ha ${ }^{-1}$ para cada $1 \%$ de incidência, e em 2007 os valores variaram entre 5,86 e $11,35 \mathrm{~kg} \mathrm{ha}^{-1}$. 
Nerbass Junior et al.

Tabela 1 - Modelos de ponto crítico para a estimativa de dano para o patossistema múltiplo ferrugem da folha e helmintosporiose da aveia branca com base na incidência foliar (I, em \%), para diferentes estádios fenológicos das cultivares 'UPFA 20 Teixeirinha' e 'UPFA 22 Temprana’ nas safras agrícolas de 2006 e 2007. Lages, SC, 2008.

\begin{tabular}{|c|c|c|c|c|c|}
\hline Cultivar/Ano & Estádio & Função Original & $\mathrm{P}^{\mathrm{a}}=$ & $\mathrm{R}^{2}$ & Função ajustada/ $\mathrm{t}^{\mathrm{b}}$ \\
\hline \multicolumn{6}{|l|}{ 'UPFA 20’ } \\
\hline \multirow{3}{*}{2006} & Alongamento & $\mathrm{R}^{\mathrm{c}}=5.641-5,95 \mathrm{I}$ & 0,144 & 0,25 & $\mathrm{R}=1.000-1,05 \mathrm{I}$ \\
\hline & Emborrachamento & $\mathrm{R}=6.345-22,07 \mathrm{I}$ & 0,019 & 0,51 & $\mathrm{R}=1.000-3,48 \mathrm{I}$ \\
\hline & Florescimento & $\mathrm{R}=5.488-4,15 \mathrm{I}$ & 0,001 & 0,78 & $\mathrm{R}=1.000-0,76 \mathrm{I}$ \\
\hline \multirow{3}{*}{2007} & Alongamento & $\mathrm{R}=6.369-55,61 \mathrm{I}$ & 0,017 & 0,53 & $\mathrm{R}=1.000-8,73 \mathrm{I}$ \\
\hline & Emborrachamento & $\mathrm{R}=6.620-40,91 \mathrm{I}$ & 0,001 & 0,83 & $\mathrm{R}=1.000-6,18 \mathrm{I}$ \\
\hline & Florescimento & $\mathrm{R}=6.129-32,34 \mathrm{I}$ & 0,001 & 0,98 & $\mathrm{R}=1.000-5,28 \mathrm{I}$ \\
\hline \multicolumn{6}{|l|}{ ‘UPFA 22’ } \\
\hline \multirow{3}{*}{2006} & Alongamento & $\mathrm{R}=5.726-17,96 \mathrm{I}$ & 0,012 & 0,57 & $\mathrm{R}=1.000-3,14 \mathrm{I}$ \\
\hline & Emborrachamento & $R=5.961-21,85 I$ & 0,005 & 0,64 & $\mathrm{R}=1.000-3,67 \mathrm{I}$ \\
\hline & Florescimento & $\mathrm{R}=6.217-36,41 \mathrm{I}$ & 0,010 & 0,58 & $\mathrm{R}=1.000-5,86 \mathrm{I}$ \\
\hline \multirow{3}{*}{2007} & Alongamento & $\mathrm{R}=5.201-41,96 \mathrm{I}$ & 0,001 & 0,38 & $\mathrm{R}=1.000-8,07 \mathrm{I}$ \\
\hline & Emborrachamento & $\mathrm{R}=5.329-60,51 \mathrm{I}$ & 0,005 & 0,49 & $\mathrm{R}=1.000-11,35 \mathrm{I}$ \\
\hline & Florescimento & $\mathrm{R}=5.604-32,83 \mathrm{I}$ & 0,001 & 0,93 & $\mathrm{R}=1.000-5,86 \mathrm{I}$ \\
\hline
\end{tabular}

${ }^{a}$ probabilidade de erro.

${ }^{\mathrm{b}}$ função ajustada por tonelada.

${ }^{\mathrm{c}}$ rendimento de grãos em quilos.

Para severidade foliar, os danos na 'UPFA 20' Teixeirinha foram de 47,16 a 51,58kg para cada $1 \%$ de severidade foliar na safra de 2006 e entre 121,6 a $586,3 \mathrm{~kg} \mathrm{ha}^{-1}$ na safra de 2007, considerando o rendimento de $1.000 \mathrm{~g} \mathrm{ha}^{-1}$ (Tabela 2). Na 'UPFA 22' Temprana, os danos variaram de 104,9 a 213,9 $\mathrm{kg} \mathrm{ha}^{-1} \mathrm{e}$ entre 125,8 a 188,3kg ha-1 em 2006 e 2007, respectivamente.

Em ambas as cultivares, a incidência e severidade foliares e os valores de dano foram maiores na safra de 2007 (Tabelas 1 e 2). Esse fato é atribuído ao monocultivo de aveia e ao atraso da época de semeadura. O primeiro, por maior potencial de inóculo de $\boldsymbol{D}$. avenae nos restos culturais, e o segundo, pelo clima mais satisfatório para $\boldsymbol{P}$. coronata (ZAMBOLIM et al., 2000). A variável incidência mostrou melhor relação com os danos, considerando os coeficientes de determinação (Tabelas 1 e 2), além de ser método objetivo e de fácil quantificação.

Para 'UPFA 20' Teixeirinha, foram obtidas cinco correlações significativas para incidência, sendo duas na safra de 2006 e três na safra de 2007 (Tabela 1) e três correlações significativas para severidade, todas na safra de 2007 (Tabela 2). Na safra de 2006, seis tratamentos obtiveram rendimento de grãos inferior ao da testemunha, não gerando gradiente de rendimento. O gradiente da doença foi gerado, o que não aconteceu com o rendimento de grãos. Tal situação ocorreu pela alta percentagem de quebra dos colmos e pelo consequente acamamento. Outro fato que contribuiu foi a ocorrência de geada no final de setembro, período próximo ao emborrachamento das plantas, uma vez que a 'UPFA 20' Teixeirinha é sensível à geada e a 'UPFA 22’ Temprana é tolerante (REUNIÃO, 2008).

Na 'UPFA 22' Temprana, todas as relações foram significativas para variável incidência (Tabela 1). Para variável severidade, com exceção da função de dano no estádio de alongamento em 2006, todas as demais relações também foram significativas (Tabela 2).

No estádio de florescimento, foram observadas equações de dano com maiores coeficientes de determinação, com probabilidade de erro inferior a $1 \%$, para incidência e severidade foliar nas duas cultivares, exceto na safra de 2006 para 'UPFA 22' Temprana (Tabelas 1 e 2). Isso indica que o rendimento de grãos sofreu interferência das diferentes intensidades das doenças foliares nesse estádio fenológico. WOLFF \& FLOSS (2008), estudando a relação entre teores de nitrogênio em folhas e rendimento de grãos em 21 cultivares de aveia branca, incluindo 'UPFA 20' Teixeirinha e 'UPFA22' Temprana, observaram que o teor de nitrogênio na folha bandeira, totalmente expandida durante o florescimento, correlaciona-se positivamente com a massa de mil grãos, o período e a taxa de enchimento de grãos e o rendimento de grãos. Entretanto, COOK et al. (1999) e BOHATCHUK et al. (2008), em trigo, e REIS et al. (2008), 
Modelos de pontos críticos para relacionar o rendimento de grãos de aveia branca com a intensidade de doença...

Tabela 2 - Modelos de ponto crítico para a estimativa de dano para o patossistema múltiplo ferrugem da folha e helmintosporiose da aveia branca com base na severidade foliar (S, em \%), para diferentes estádios fenológicos das cultivares 'UPFA 20 Teixeirinha' e ‘UPFA 22 Temprana’ nas safras agrícolas de 2006 e 2007. Lages, SC, 2008.

\begin{tabular}{|c|c|c|c|c|c|}
\hline Cultivar/Ano & Estádio & Função Original & $\mathrm{P}^{\mathrm{a}}=$ & $\mathrm{R}^{2}$ & Função ajustada/ $\mathrm{t}^{\mathrm{b}}$ \\
\hline \multicolumn{6}{|l|}{ 'UPFA' 20} \\
\hline \multirow{3}{*}{2006} & Alongamento & $\mathrm{R}^{\mathrm{c}}=5.505-259,6 \mathrm{~S}$ & 0,134 & 0,26 & $R=1.000-47,16 S$ \\
\hline & Emborrachamento & $R=5.698-561,5 S$ & 0,064 & 0,37 & $R=1.000-98,54 S$ \\
\hline & Florescimento & $\mathrm{R}=5.459-281,6 \mathrm{~S}$ & 0,061 & 0,49 & $R=1.000-51,58 S$ \\
\hline \multirow{3}{*}{2007} & Alongamento & $\mathrm{R}=4.965-2.911 \mathrm{~S}$ & 0,001 & 0,34 & $\mathrm{R}=1.000-586,3 \mathrm{~S}$ \\
\hline & Emborrachamento & $\mathrm{R}=5.181-1.702 \mathrm{~S}$ & 0,002 & 0,55 & $\mathrm{R}=1.000-328,5 \mathrm{~S}$ \\
\hline & Florescimento & $\mathrm{R}=5.252-638,6 \mathrm{~S}$ & 0,001 & 0,89 & $R=1.000-121,6 S$ \\
\hline \multicolumn{6}{|l|}{ 'UPFA' 22} \\
\hline \multirow{3}{*}{2006} & Alongamento & $\mathrm{R}=5.161-541,5 \mathrm{~S}$ & 0,063 & 0,37 & $R=1.000-104,9 S$ \\
\hline & Emborrachamento & $\mathrm{R}=5.433-966,8 \mathrm{~S}$ & 0,014 & 0,54 & $\mathrm{R}=1.000-177,9 \mathrm{~S}$ \\
\hline & Florescimento & $\mathrm{R}=5.539-1.185 \mathrm{~S}$ & 0,001 & 0,74 & $R=1.000-213,9 S$ \\
\hline \multirow{3}{*}{2007} & Alongamento & $\mathrm{R}=4.977-657,8 \mathrm{~S}$ & 0,001 & 0,60 & $R=1.000-132,1 S$ \\
\hline & Emborrachamento & $\mathrm{R}=4.238-798,1 \mathrm{~S}$ & 0,013 & 0,55 & $\mathrm{R}=1.000-188,3 \mathrm{~S}$ \\
\hline & Florescimento & $\mathrm{R}=4.680-588,5 \mathrm{~S}$ & 0,001 & 0,78 & $\mathrm{R}=1.000-125,8 \mathrm{~S}$ \\
\hline
\end{tabular}

${ }^{\text {a }}$ probabilidade de erro.

b função ajustada por tonelada.

${ }^{\text {c }}$ rendimento de grãos em quilos.

em aveia branca, obtiveram maiores danos em estádios iniciais, uma vez que o surgimento precoce das doenças pode interferir no número de grãos por espiga e número de grãos por $\mathrm{m}^{-2}$.

$\mathrm{Na}$ análise das diferenças entre os maiores rendimentos e as testemunhas, foi constatada redução de produção causada pelas doenças foliares de $260,4 \mathrm{~kg}$ ha-1 na 'UPFA 20' Teixeirinha e 1.283,8kg ha ${ }^{-1}$ na 'UPFA 22' Temprana em 2006. Na safra de 2007, a redução foi de $2.790,2 \mathrm{~kg} \mathrm{ha}^{-1} \mathrm{na}$ 'UPFA 20' Teixeirinha e $2.509,0 \mathrm{~kg}$ ha $^{-1}$ na 'UPFA22' Temprana. As reduções no rendimento de grãos corresponderam a danos de 4,7, 23,5, 50,3 e 48,4\% respectivamente. Funções de dano são descritas para doenças específicas em trigo (REIS et al., 2000), cevada (REIS et al., 2002), milho (REIFSCHNEIDER \& ARNY, 1983; NUTTER \& JENCO, 1992; WARD et al. 1999; REIS et al., 2007) e aveia branca (REIS et al., 2008). As funções, neste trabalho, para patossistema múltiplo, em diferentes estádios fenológicos, consideram que os danos no rendimento são decorrentes da redução da área foliar fotossintética, ao considerar a ocorrência simultânea da helmintosporiose e ferrugem, uma vez que cultivares de aveia branca disponíveis apresentam no campo suscetibilidade a mais de uma doença (REUNIÃO, 2008). De cada função, pode-se obter os coeficientes de dano, os quais podem ser utilizados no cálculo do LDE, que é um critério para tomada de decisão de aplicação de fungicidas que leva em consideração aspectos técnicos, econômicos e ambientais.

\section{CONCLUSÕES}

A relação entre incidência e severidade foliares, pela ocorrência simultânea da ferrugem da folha e helmintosporiose, com o rendimento de grãos de aveia branca, gera coeficientes de dano pelo modelo de ponto crítico utilizados para o cálculo do limiar de dano econômico. A cultivar 'UPFA 22' Temprana apresenta maiores valores de coeficientes de dano. $\mathrm{O}$ estádio de florescimento apresenta maior relação entre os coeficientes de dano, tanto pela incidência, quanto pela severidade. A incidência demonstra melhor relação com os danos.

\section{REFERÊNCIAS}

BERGAMIN FILHO, A.; AMORIM, L. Doenças de plantas tropicais: epidemiologia e controle econômico. São Paulo: Agronômica Ceres, 1996. 289p.

BOHATCHUK, D.A. et al. Modelo de ponto crítico para estimar danos de doenças foliares do trigo em patossistema múltiplo. Tropical Plant Pathology. v.33, p.354-360, 2008. Disponível em: <http:/ /www.scielo.br/scielo.php?script=sci_arttext\&pid=S1982$56762008000500004 \& \operatorname{lng}=p t \& n r m=i s o \& t \operatorname{lng}=p t>$. Acesso em: 03 set. 2009. doi: 10.1590/S1982-56762008000500004.

CONAB. Indicadores agropecuários. Disponível em: www.conab.gov.com. On line. Acesso em: set. 2007.

COOK, R.J. et al. Effects of fungicide spray timing on winter wheat disease control. Plant Pathology, v.48, p.33-50, 1999. 
EMBRAPA. Sistema Brasileiro de Classificação de Solos. Disponível em: www.cnps.embrapa.br/sibcs/. On line. Acesso em: mar. 2008.

LOSS, E.L. (Org.). Resultados experimentais da XXVII Reunião da Comissão Brasileira de Pesquisa de Aveia. Passo Fundo-RS: UPF, 2007. V.300, 438p.

FORCELINI, C.A.; REIS, E.M. Doenças da aveia . In: KIMATI, H. et al. (Org.). Manual de fitopatologia: doenças das plantas cultivadas. 4.ed. São Paulo: Agronômica Ceres, 2005. V.2, p.95-98.

INDICAÇÕES TÉCNICAS DA COMISSÃO BRASILEIRA DE PESQUISA DE TRIGO - TRIGO E TRITICALE - 2008. I Reunião da Comissão Brasileira de Pesquisa de Trigo. Londrina, 2008. 147p.

JESUS JUNIOR, W.C. et al. Quantificação de danos e perdas. In: VALE, F.X.R. et al. Epidemiologia aplicada ao manejo de doenças de plantas. Belo Horizonte, MG: Perffil, 2004. p.273-203.

MARTINELLI, J.A. et al. Redução do rendimento de grãos da aveia em função da severidade da ferrugem da folha. Summa Phytopathologica, v.20, p.116-118, 1994.

NUTTER, F.W.; JENCO, J.H. Development of a critical-point yield loss model to estimate yield losses in corn caused by Cercospora zeae-maydis. Phytopathology, v.82, p.990-994, 1992.

REIFSCHNEIDER, F.J.B.; ARNY, D.C. Yield loss of maize caused by Kabatiella zeae. Phytopathology, v.73, p.607-609, 1983.

REIS, E.M.; CASA, R.T. Doenças dos cereais de inverno: diagnose, epidemiologia e controle. 2.ed. Rev. Atual. Lages: Graphel, 2007. 176p.

REIS, E.M. et al. Modelos de ponto crítico para estimar danos causados pela ferrugem da folha da aveia branca. Summa Phytopathologica, v.34, p.238-241, 2008.
REIS, E.M. et al. Modelo de ponto crítico para estimar os danos causados pelo oídio em cevada. Fitopatologia Brasileira, v.27, p.644-646, 2002. Disponível em: <http://www.scielo.br/ s c i e l o.ph p ? s c ri p t = s c i_a r t text \& pi d = S 0100 $41582002000600016 \& \operatorname{lng}=p t \& \mathrm{nrm}=\mathrm{iso} \& \mathrm{t} \operatorname{lng}=\mathrm{pt}>$. Acesso em: 03 set. 2009. doi: 10.1590/S0100-41582002000600016.

REIS, E.M. et al. Efeito da ferrugem da folha no rendimento de grãos de trigo. Fitopatologia Brasileira, v.25, p.67-71, 2000.

REIS, E.M. et al. Critical-point yield model to estimate yield damage caused by Cercospora zea-maydis in corn. Fitopatologia Brasileira, v.32, p.110-113, 2007. Disponível em: < http:// www.scielo.br/scielo.php?script=sci_arttext \&pid=S010041582007000200003\&lng=pt\&nrm=iso\&tlng=en $>$. Acesso em: 03 set. 2009. doi: 10.1590/S0100-41582007000200003.

REUNIÃO DA COMISSÃO BRASILEIRA DE PESQUISA DE AVEIA. Indicações técnicas para a cultura da aveia. Pelotas, 2008. 92p.

SAH, D.N.; MACKENZIE, D.R. Methods of generating different levels of disease epidemics in loss experiments. In TENG, P.S. (Ed.). Crop loss assessement and pest management. St. Paul, MN: American Phytopathological Society, 1987. p.9095.

ZAMBOLIM, L. et al. Sistema plantio direto e doenças em plantas. Fitopatologia Brasileira, v.25, p.585-595, 2000.

WARD, J.M.J. et al. Gray leaf spot: a disease of global importance in maize production. Plant Disease, v.83, p.884895, 1999.

WOLFF, W.M.; FLOSS, E.L. Correlação entre teores de nitrogênio e de clorofila na folha com o rendimento de grãos de aveia branca. Ciência Rural, v.38, p.1510-1515, 2008. Disponível em: <http:/ /www.scielo.br/scielo.php?script=sci_arttext\&pid=S010384782008000600003\&lng=pt\&nrm=iso\&tlng=pt>. Acesso em: 03 set. 2009. doi: 10.1590/S0103-84782008000600003. 